\title{
Publication Report
}

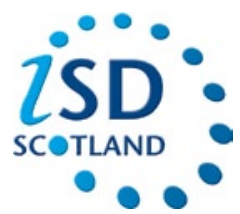

\section{Births in Scottish Hospitals}

Year ending 31 March 2010

Publication date - 30 August 2011 


\section{Contents}

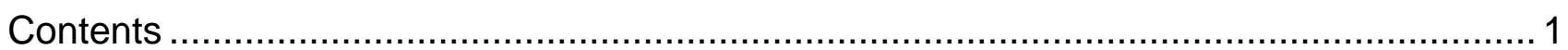

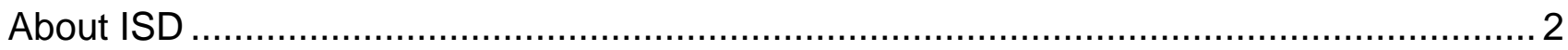

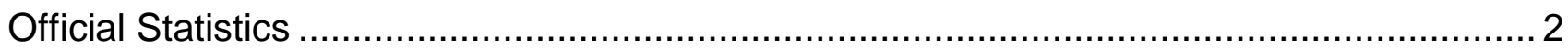

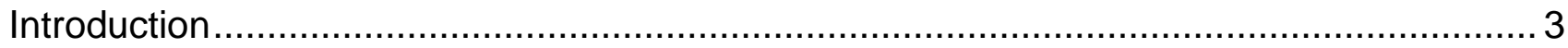

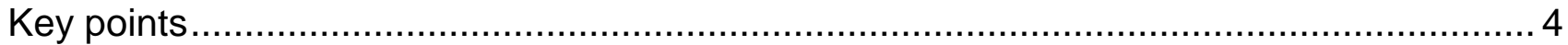

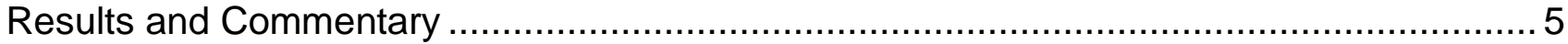

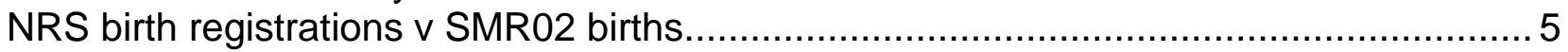

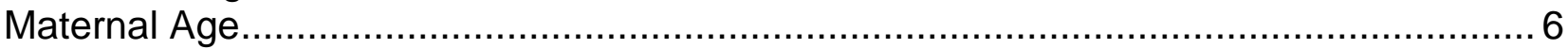

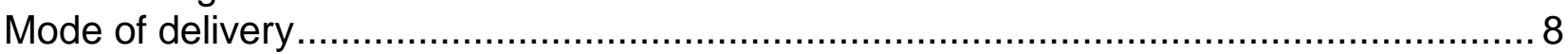

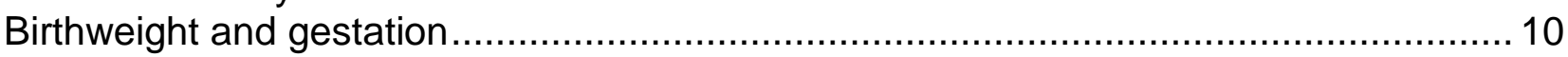

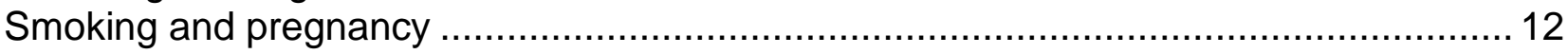

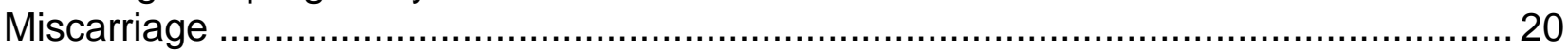

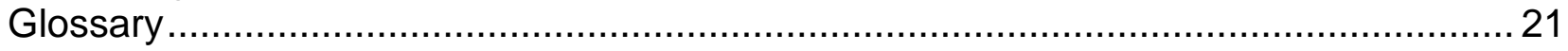

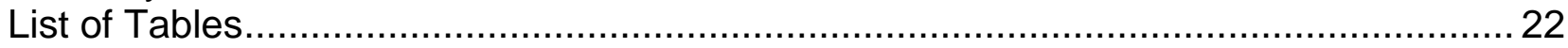

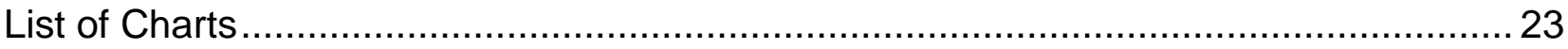

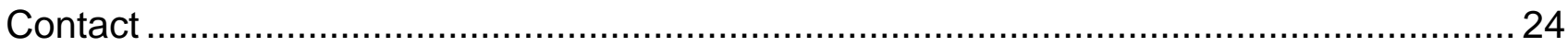

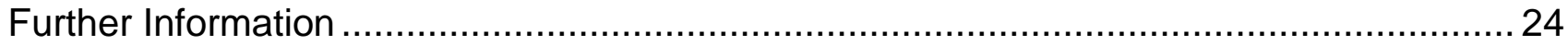

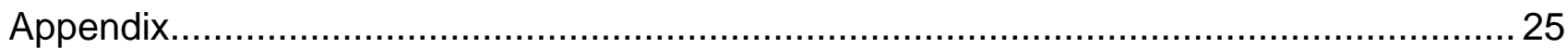

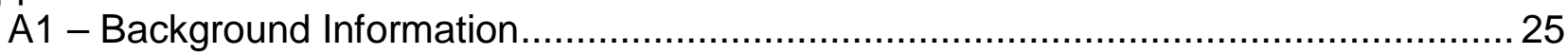

A2 - Publication Metadata (including revisions details) ....................................... 28

A3 - Early Access details (including Pre-Release Access) ................................... 30 


\section{About ISD}

Scotland has some of the best health service data in the world combining high quality, consistency, national coverage and the ability to link data to allow patient based analysis and follow up.

Information Services Division (ISD) is a business operating unit of NHS National Services Scotland and has been in existence for over 40 years. We are an essential support service to NHSScotland and the Scottish Government and others, responsive to the needs of NHSScotland as the delivery of health and social care evolves.

Purpose: To deliver effective national and specialist intelligence services to improve the health and wellbeing of people in Scotland.

Mission: Better Information, Better Decisions, Better Health

Vision: To be a valued partner in improving health and wellbeing in Scotland by providing a world class intelligence service.

\section{Official Statistics}

Information Services Division (ISD) is the principal and authoritative source of statistics on health and care services in Scotland. ISD is designated by legislation as a producer of 'Official Statistics'. Our official statistics publications are produced to a high professional standard and comply with the Code of Practice for Official Statistics. The Code of Practice is produced and monitored by the UK Statistics Authority which is independent of Government. Under the Code of Practice, the format, content and timing of statistics publications are the responsibility of professional staff working within ISD.

ISD's statistical publications are currently classified as one of the following:

- National Statistics (ie assessed by the UK Statistics Authority as complying with the Code of Practice)

- National Statistics (ie legacy, still to be assessed by the UK Statistics Authority)

- Official Statistics (ie still to be assessed by the UK Statistics Authority)

- other (not Official Statistics)

Further information on ISD's statistics, including compliance with the Code of Practice for Official Statistics, and on the UK Statistics Authority, is available on the ISD website. 


\section{Introduction}

The data presented here are mainly obtained from the Scottish Morbidity Record 02 (SMR02) submitted by maternity hospitals to ISD, who have collected this information since 1975.

A wide range of information is collected on the SMRO2 - some of which are detailed below:

- mother - age, height, smoking history, previous obstetric history.

- birth - induction, analgesia, method of delivery, outcome.

- baby - apgar score, sex, gestation, weight.

Although there is no legal requirement to submit these data to ISD, the level of submission falls only slightly short of the known total number of births occurring each year. Further details are shown on the first chart in the Results and Commentary section - this shows a comparison of births recorded on SMR02 compared to number of births registered with the National Records of Scotland (NRS). See also background information (Appendix 1).

\section{Revision of smoking at First Visit figures}

The smoking in pregnancy section also includes figures on maternal smoking as recorded at the public health nurse/health visitor's First Visit review. This information is recorded on the pre-school component of the Child Health Systems Programme (CHSP-PS). A new methodology has been implemented to improve the accuracy of the NHS Board and Scottish Index of Multiple Deprivation (SIMD 2009) quintile statistics on maternal smoking at the First Visit. The overall Scotland figures and data by maternal age are not affected by the new methodology. This revision does not affect the overall interpretation or conclusions to be drawn from previously published data. For further information see Appendix A1. 


\section{Key points}

- Babies born in Scotland: There were 58,356 births recorded on SMR02 for year ending March 2010. This compares to 58,884 (provisional) births registered in Scotland by the National Records Service in the same time period.

- Mothers are getting older: There was a steady increase in the proportion of births to mothers aged 30-34, from 13\% in 1976 to a peak of 31\% in 2002, but this has now declined slightly to $27 \%$ in 2010 . The proportion of births to mothers in the 35-39 group climbed steadily to $17 \%$ in 2008 from $4 \%$ twenty years ago and has now decreased to $16 \%$. Nearly $4 \%$ of births are to mothers aged forty and over compared to less than $1 \%$ during the 1980s.

- Smoking in pregnancy: The overall percentage of women who reported smoking at the time of their first antenatal booking has decreased consistently from 29.0\% in 1995 to $18.8 \%$ in 2010 . However, it should be noted that the percentage of 'unknowns' has risen from 5\% in 1995 to $10.7 \%$ in 2010 and that this may include a proportion of smokers. This is an improvement on 2009, when 'unknowns' accounted for $14.2 \%$. There is known to be considerable under-reporting of smoking by pregnant women themselves.

- Caesarean section: In singleton births, the emergency caesarean section rate increased from $3.9 \%$ in 1976 to a peak of $15.4 \%$ in 2006 , followed by a slight drop in the last 4 years to $14.8 \%$. The rate of elective* or planned caesarean sections has continued to rise from $4.7 \%$ in 1976 , to $10.5 \%$ in 2010 . Together this has resulted in an overall increase in caesarean section rates from $8.6 \%$ in 1976 to $25.4 \%$ in 2010.

[ ${ }^{\star}$ An elective caesarean section refers to a caesarean section which has been planned in advance and in most cases will have been recommended for clinical reasons such as breech or multiple births or previous caesarean section. It may also be the case that the woman will have chosen this method of delivery for non-clinical reasons.]

- Forceps deliveries: After falling from $13.5 \%$ in 1980 to $6.8 \%$ in 2001 the use of forceps in delivery has risen over the last 9 years and is now at $9.7 \%$.

- Premature babies: The percentage of pre-term (born before 37 completed weeks) singleton babies rose from 5.2\% in 1976 to a peak of 6.7 in 2004 and has now fallen to $6.0 \%$ in 2010; the lowest since rate 1998.

- Deprivation: The most common age for starting a family in areas of low deprivation is 31 , which is 10 years later than the most common age in areas of high deprivation.

- Low birthweight: For singleton births, a mother living in an area of high deprivation is twice as likely to have a low birthweight baby (under $2500 \mathrm{~g}$ ) compared to a mother living in an area of low deprivation.

- Miscarriage: There is a general downward trend in the number of recorded miscarriages, falling from 7546 in 1998 to 5708 in 2010 . However, it is likely that some, particularly early, miscarriages are either managed solely by General Practitioners or may not be recognised by the women and so are never referred to hospital. 


\section{Results and Commentary}

\section{NRS birth registrations v SMR02 births}

Since 1855 all births in Scotland have been registered with the National Records of Scotland (NRS) previously the General Register Office for Scotland. The chart below shows an initial rise to around 120,000 births per year in the early 1900 s then a general downward trend to just over 50,000 in 2002 . Since then there has been a steady year on year increase to a peak in 2008 of 60,041 live births. The 2010 provisional NRS figures show that the number of live births was 58,791 , representing a decrease of $2.1 \%$ from 2008.

NRS birth registrations v SMR02 births; yle 31 December 1855 to $2010^{p}$

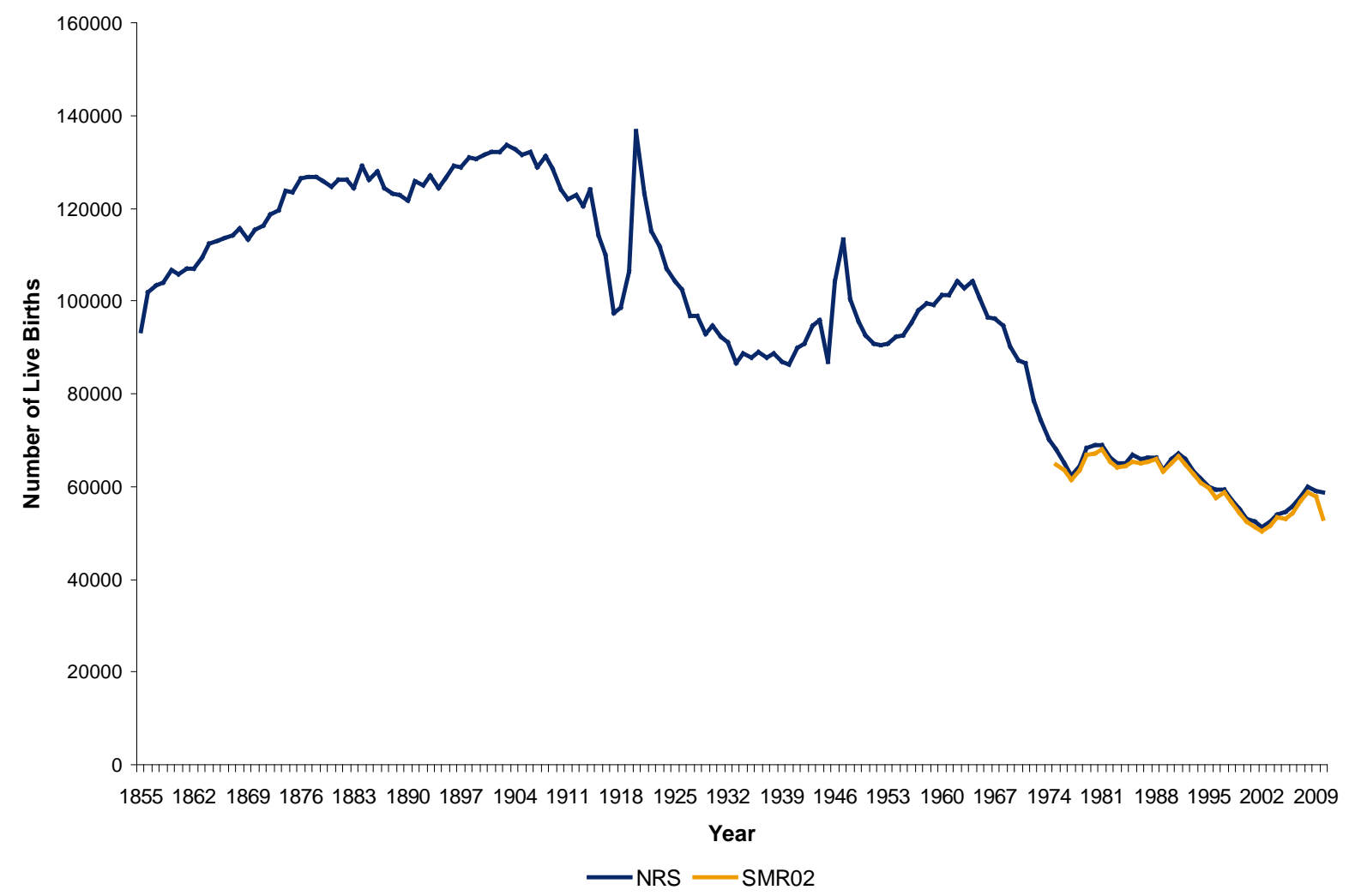

Sources: NRS birth registrations and SMR02.

P Provisional.

The apparent SMR02 fall-off in 2010 relates to data submission problems in the second half of 2010.

For information on outcome of births see:

Table 1: Births by outcome and year; Scotland, NHS board, LCA and CHP 


\section{Maternal Age}

There has been an increase in the proportion of babies born to women over the age of thirty. It is well established that women are having fewer children, and postponing childbirth until they are older as shown in Table 2. Births to mothers aged 30-34 have risen steadily, accounting for $27 \%$ of all maternities. Since 1976 there has also been a steady rise in the proportion of mothers aged 35+ (from 6.0\% to 19.7\%). In 1976 there were 18,000 more births to mothers in the 20-24 group compared to those in the 35+ group; however, this gap has diminished steadily in the intervening years, such that in 2010 there were nearly 400 more births to mothers aged 35+. This change has obstetric implications and has contributed to the rise in caesarean sections, since it is well documented that age is correlated with increased risk of emergency caesarean section.

Table 3 shows the number of first births divided into deprivation quintile, which are derived from the total population rather than just the childbearing population. Although $20 \%$ of the total population are classified into each quintile, there is an imbalance between the least and the most deprived quintiles of the childbearing population with a higher proportion of births in quintile 1 (most deprived) compared with quintile 5 (least deprived). However, when the data are examined by age, there are strong patterns as shown in the chart below.

\section{First birth ${ }^{1,2}$ by maternal age and deprivation quintile ${ }^{3}$; yle $31{\text { March } 2010^{p}}^{p}$}

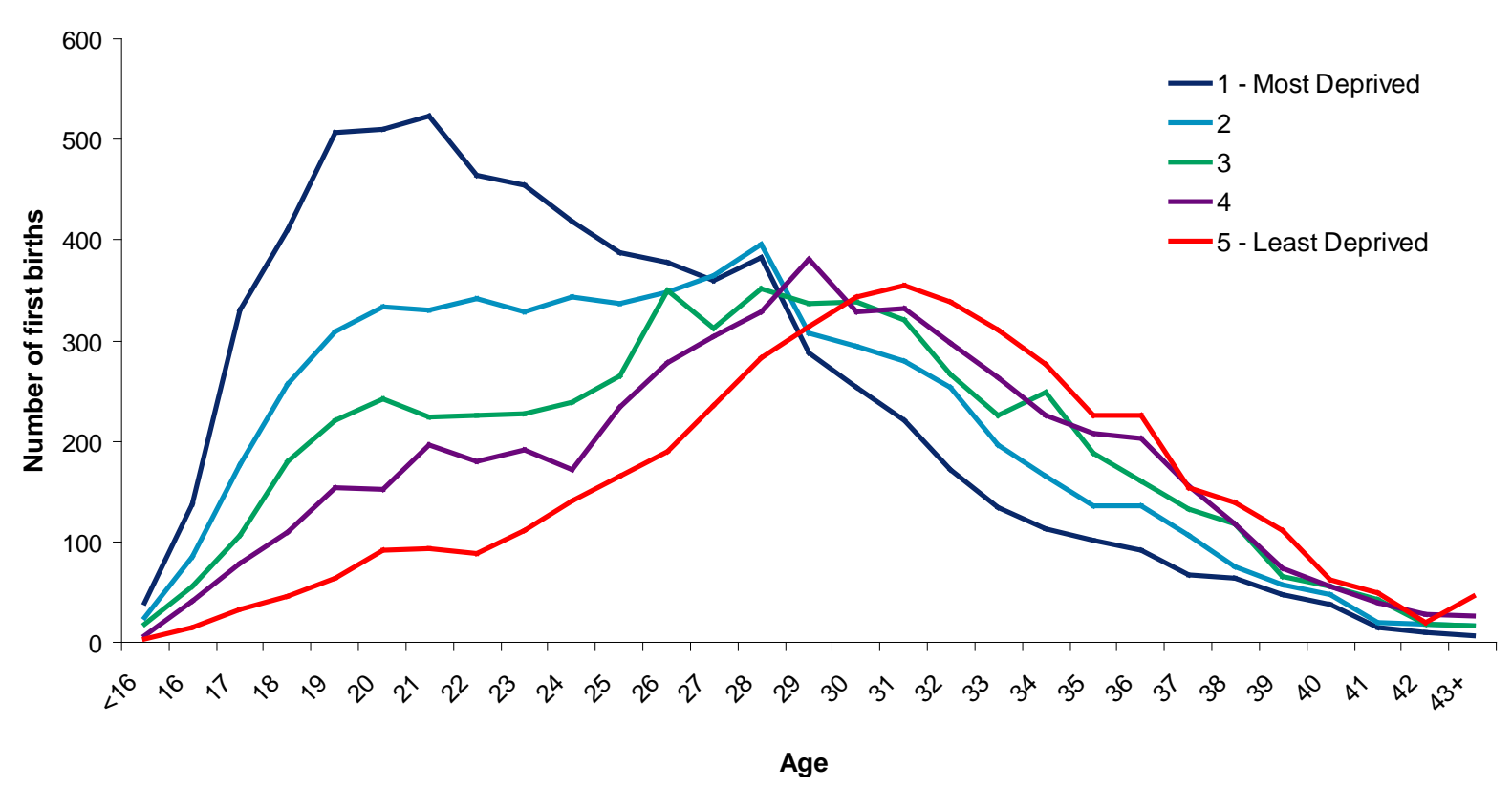

\section{Source: SMR02}

1. Excludes home births and births at non NHS hospitals.

2. Where four or more babies are involved in a pregnancy, birth details are recorded only for the first three babies delivered.

3. Scottish Index of Multiple Deprivation (SIMD) 2009.

$\mathrm{P}$ Provisional. 
The age distribution of first births by deprivation shows a difference of approximately 10 years between the most common age for starting a family in the most deprived quintile compared to the least deprived. In the under 20 s, there were nearly nine times the proportion of births in the more deprived groups compared to the least deprived, and this pattern has remained fairly constant, despite a decrease of nearly $50 \%$ in the total number of births in this age group since 1976. In the 20-24 year olds the ratio of babies born in quintile 5 (least deprived) to the number born in quintile 1 is approximately four to one. This starts to reverse at approximately 28 years, and for the combined age groups 30-34 and 35-39, the ratio is one to two. Again, there has been little change in this proportion in recent years. Much the same sort of pattern is seen when all births are examined rather than just first births. The data support the view that these changes in behaviour (delaying reproduction and having smaller families) are occurring in all sections of society.

For more information on births by maternal age see:

Table 2: Maternities by maternal age and year; Scotland, NHS board, LCA and CHP Table 3: Maternities (first birth and all births), by maternal age and deprivation (SIMD); Scotland and by NHS board by year 


\section{Mode of delivery}

\section{Singleton births}

In singleton births, spontaneous vertex (normal vaginal) deliveries have fallen steadily since 1976 from (75.8\% to $61.7 \%)$. Forceps deliveries have fallen from $13.3 \%$ in 1976 to a low of $6.8 \%$ in 2002 before rising to $9.7 \%$ in 2010 . The chart below illustrates the changes in mode of delivery since 1998.

\section{Live singleton births ${ }^{1,2}$ by mode of delivery (excluding SVD); 1998-2010, yle 31 March}

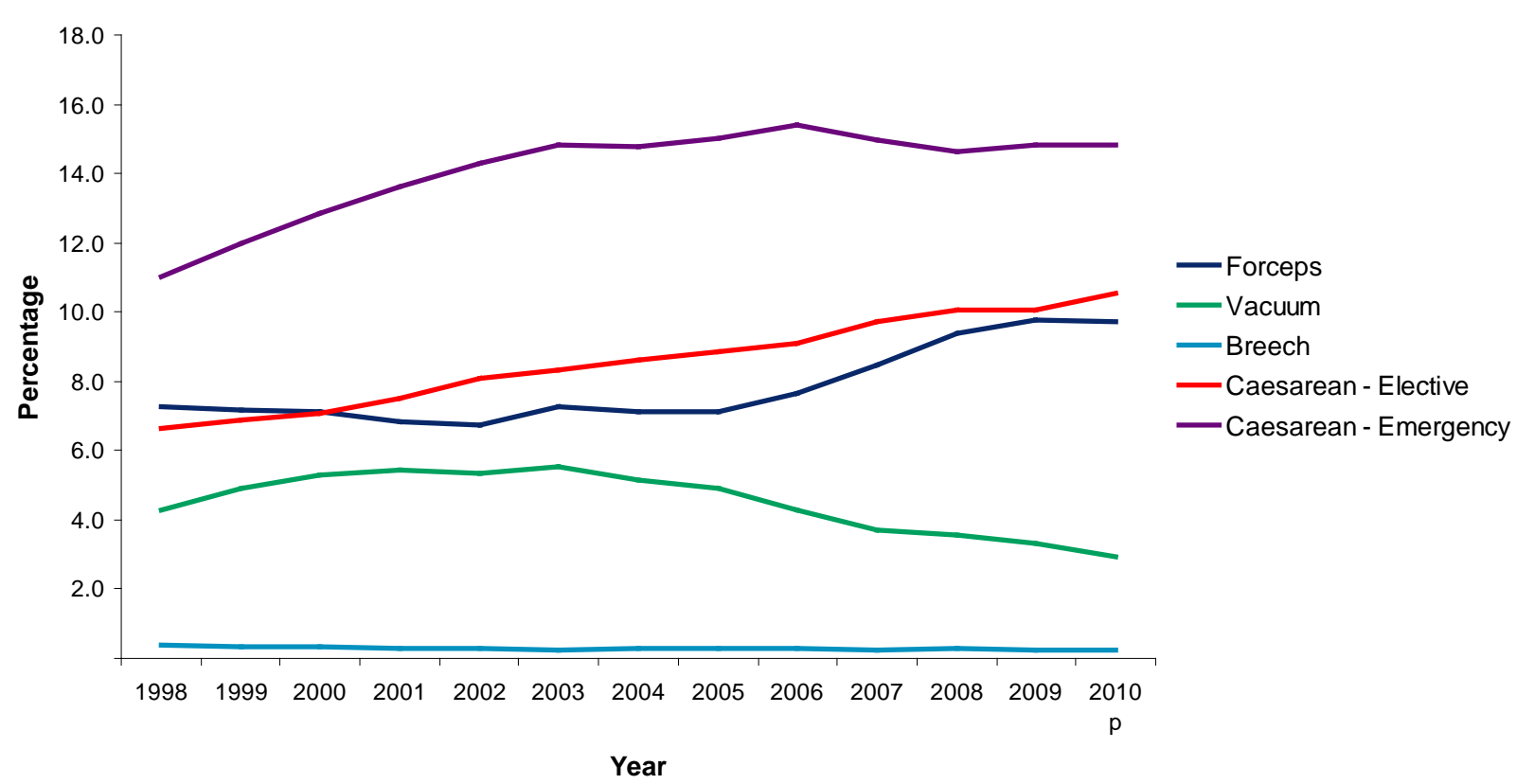

Source: SMR02

1. Excludes home births and births at non NHS hospitals.

2. Where four or more babies are involved in a pregnancy, birth details are recorded only for the first three babies delivered.

P Provisional.

Elective* and emergency caesarean section rates have both increased steadily since 1976 (from $4.7 \%$ to $10.5 \%$ and $3.9 \%$ to $14.8 \%$ respectively). The overall caesarean section rate has risen from $8.6 \%$ in 1976 to $25.4 \%$ in 2010 . Possible explanations for this rise include demographic changes, differences in clinical practice, characteristics and views of the obstetrician, the organisation and availability of resources, one to one support in labour and womens' choices. The change in practice for delivery of breech presentation, repeat caesarean section, delivery of preterm infants and twins are contributing to the overall rise. In addition maternal age and weight are rising and this has been shown to correlate with a rise in caesarean section ${ }^{1}$.

Ventouse (vacuum extraction) was less than 1\% until 1990 then rose to $5.6 \%$ in 2003. Since then there has been a steady decline to $2.9 \%$ in 2010 . Vaginal breech delivery has fallen slowly but steadily from $1.7 \%$ in 1976 to $0.2 \%$. In 1976 rates of induction of labour were $47.6 \%$ and then fell steadily to reach a low of $20.3 \%$ in 1989 . Since 1989 , rates of 
induction rose and then fluctuated at around $27 \%$, but are once again showing a steady decline over the last few years, with a rate of $22.4 \%$ in 2010 . Population studies have shown a rise in perinatal and neonatal morbidity and mortality in prolonged pregnancies which has led to current recommendations for considering induction of labour after 41 completed weeks ${ }^{2,3}$.

\section{Multiple births}

Multiple births are less likely to be delivered vaginally, with $35.4 \%$ being delivered by elective caesarean section (compared to $6.1 \%$ in 1976) and $30.3 \%$ by emergency section (compared to $4.5 \%$ in 1976). The incidence of multiple births is rising partly because of an older maternal population (multiple births are more common with increasing maternal age) and the use of ovulation induction and IVF (In Vitro Fertilisation).

* An elective caesarean section refers to a caesarean section, which has been planned in advance and in most cases will have been recommended for clinical reasons such as breech or multiple births or previous caesarean section. It may also be the case that the woman will have chosen this method of delivery for non-clinical reasons.

For more information on mode of delivery see:

Table 4: Live births by mode of delivery (and induced) by year; Scotland, NHS board and hospital.

\section{References:}

1. National Sentinel Caesarean Section Audit Report. October 2001

2. Gülmezoglu AM, Crowther CA, Middleton $P$. Induction of labour for improving birth outcomes for women at or beyond term. Cochrane Database of Systematic Reviews 2006, Issue 4. Art. No.: CD004945. DOI: 10.1002/14651858.CD004945.pub2.

3. http://www.nice.org.uk/nicemedia/live/12012/41255/41255.pdf 


\section{Birthweight and gestation}

\section{Singleton births}

Low birthweight (LBW) is a major determinant of infant mortality and morbidity. In addition, as it is associated with a variety of social and environmental factors, it is often used as a health status indicator. Low birthweight may result from being born too soon (i.e. a preterm birth), from poor intrauterine growth or from a combination of the two.

A number of factors have been shown to be associated with low birthweight and/or preterm births. These include maternal smoking, maternal age (older and younger mothers are more likely to have a low birthweight baby), deprivation, previous obstetric history, low prepregnancy maternal weight, drug/alcohol use, hypertension and multiple births. Information on some of these factors is also recorded and available on these web pages: maternal age; smoking at booking and maternal smoking recorded at public health nurse/health visitor's First Visit.

The chart below shows trends in the proportions of babies born of low (1500-2499g) and very low (under $1500 \mathrm{~g}$ ) birthweight (VLBW) at full term (at or after 37 weeks gestation) and pre-term (before 37 weeks gestation) for singleton births.

\section{Live singleton births ${ }^{1,2}$ by birthweight and gestation; 1998-2010, y/e 31 March}

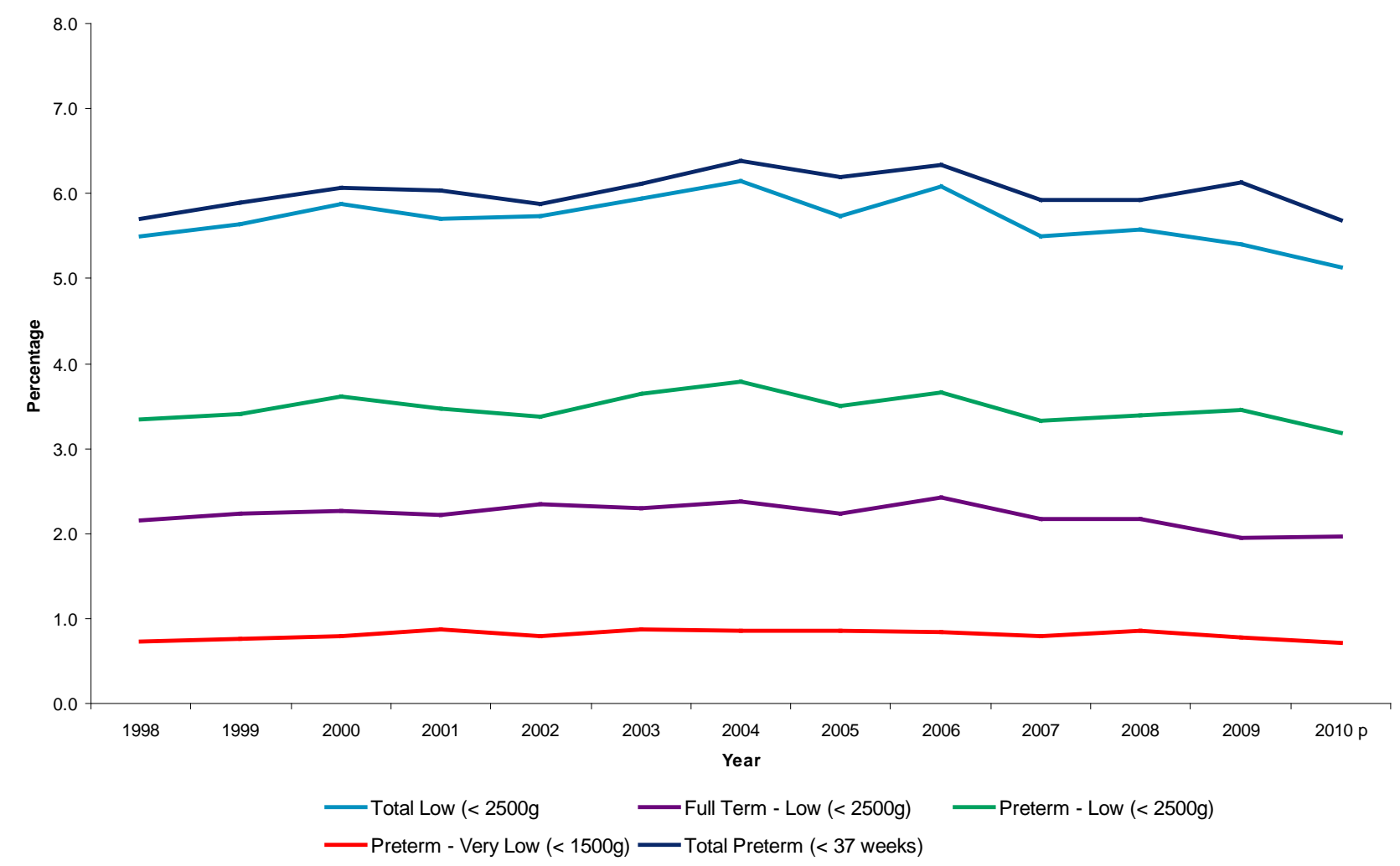

Source: SMR02

1. Excludes home births and births at non NHS hospitals.

2. Where four or more babies are involved in a pregnancy, birth details are recorded only for the first three babies delivered.

3. Includes births where the birthweight is unknown.

P Provisional. 


\section{Small and large for gestational age}

Birthweight is one of the important indicators used to assess the health of an infant at birth and there has been an overall rise in mean birthweight in recent years. However, it is important to be able to differentiate between babies who are light because they are premature and those who are inappropriately light after adjustment for gestational age at birth. Such babies, known as "small for gestational age" may be growth restricted and have an increased risk of other complications. Some of the babies who are large for gestational age may be macrosomic secondary to maternal diabetes.

The data in the accompanying charts and tables is presented for live births and has been produced by comparing the birthweights and gestations with a set of standard tables derived from Scottish data on all births from the years 1998-2003. The details of the way in which the standards were derived are available here: http://www.biomedcentral.com/1471$\underline{2393 / 8 / 5}$

\section{Singleton livebirths; Proportion under 5th Centile ${ }^{1}$ - Small for Gestational Age ${ }^{2,3}$ in Scotland ${ }^{4}$; yle 31 March}

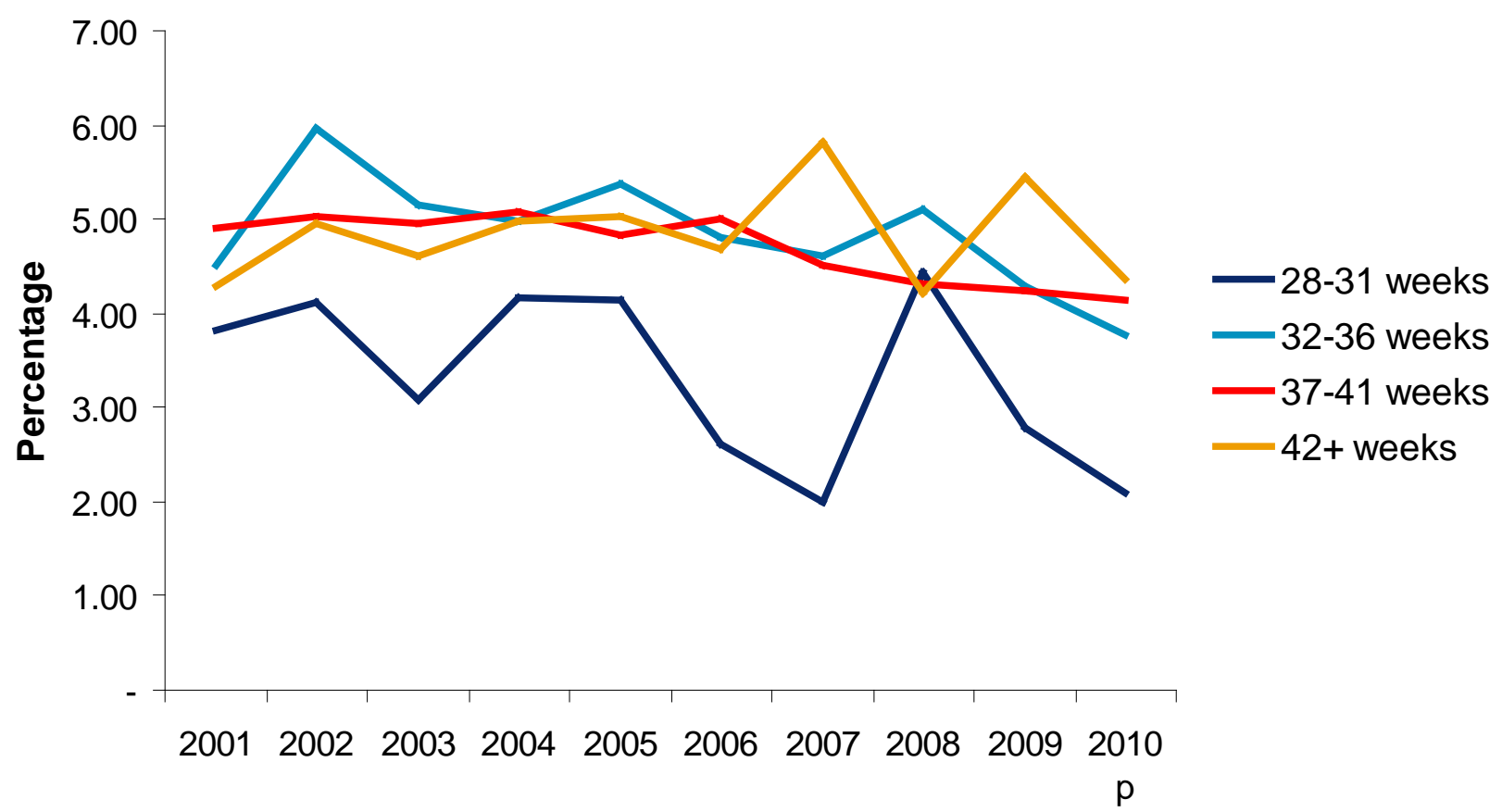

Year ending 31 March

\section{Source: SMR02}

1 - Centile Charts for Birthweight Charts for Gestational Age for Scottish Singleton Births, Sandra Bonnellie et al, BMC Pregnancy and Child Birth 2008, 8:5

2 - Excludes home births and births at non-NHS hospitals.

3 - Where four or more babies are involved in a pregnancy, birth details are recorded only for the first three babies delivered.

4 - Scotland data includes births where NHS board of residence is unknown or outside Scotland.

p - Provisional.

For more information on birthweight and gestation see:

Table 5: Live births by birthweight, gestation and year; Scotland and NHS board

Table 6: Births by term, birthweight and year; Scotland and NHS board

Table 7: Live births by birthweight, deprivation and year; Scotland and NHS board

Table 11: Small for gestational age 


\section{Smoking and pregnancy}

It is widely accepted that smoking during pregnancy is harmful to both mother and baby. As mentioned in the Birthweight and Gestation section, maternal smoking is associated with preterm and/or low birthweight babies. Smoking in pregnancy is also associated with increased risk of miscarriage, stillbirth and sudden unexpected death in infancy (SUDI). The Scottish Stillbirth Perinatal and Infant Mortality and Morbidity Report provides information on the incidence of stillbirth and SUDI.

Smoking behaviour in pregnancy is collected at a woman's first antenatal booking appointment which usually takes place within the first three months of pregnancy. These booking appointments take place either at hospital or in the community and are recorded on the Scottish Woman Held Maternity Record, with data being subsequently transcribed onto the Scottish Morbidity Record (SMR02). Information on maternal smoking is also recorded at the public health nurse/health visitor's First Visit to the mother and baby which usually takes place about 10 days after the birth. Data from the First Visit is recorded on the Pre-school component of the Child Health Systems Programme (CHSP-PS).The CHSP-PS was introduced in 1991 and the number of participating boards has increased over the years. All NHS Boards in Scotland now use the CHSP-PS, however data are not presented for NHS Grampian and NHS Orkney as these Boards had not implemented the system for the time period reported. The 12 NHS boards using the system in financial year 2009/10 account for approximately 89 percent of Scotland's pre-school population.

In recent years, there have been concerns about the completeness and quality of the SMR02 data, and to a lesser extent, the CHSP-PS data. In the following charts, we present the data so that the reader can see the level of recording of all responses including 'unknown', and they can also compare the two systems. It should be noted that the CHSPPS data does not record whether the woman was a 'former' smoker. The label of 'missing' in the CHSP-PS data is assumed to be equivalent to the label of 'Not Known' in the SMR02 data.

There is considerable pressure on women not to smoke during pregnancy, and there is evidence of under-reporting by women of their smoking behaviour at the booking clinic $^{1}$. The public health nurses/health visitors perform their First Visit at home, so it is less easy for the mother to hide evidence of smoking.

Charts showing overall smoking rates, deprivation categories, NHS board and mother's age for 'Smoking history at Booking' and 'Smoking at public health nurse/health visitor's first visit' are shown on the following pages. Please refer to footnotes relevant to charts at end of Smoking and Pregnancy section.

Revision of maternal smoking at First Visit figures: A new methodology has been implemented to improve the accuracy of the NHS Board and Scottish Index of Multiple Deprivation (SIMD 2009) quintile statistics on maternal smoking at the First Visit for all years presented. The overall Scotland figures and data by maternal age are not affected by the new methodology. This revision does not affect the overall interpretation or conclusions to be drawn from previously published data. For further information see Appendix A1. 
Links to the tables are available here:

Table 8: Smoking history at booking; Scotland, NHS board, deprivation and maternal age

Table 9: Smoking at public health nurse/health visitor's first visit; Scotland, NHS board, deprivation and maternal age

\section{Reference:}

1. Shipton D, Tappin D, Vadiveloo T, Crossley J, Aitken D, Chalmers J. Reliability of self reported smoking status by pregnant women for estimating smoking prevalence: a retrospective, cross sectional study. BMJ 2009;339:b4347. 


\section{Overall smoking rates}

Smoking at booking; $2001-2010^{p}$, yle 31 March

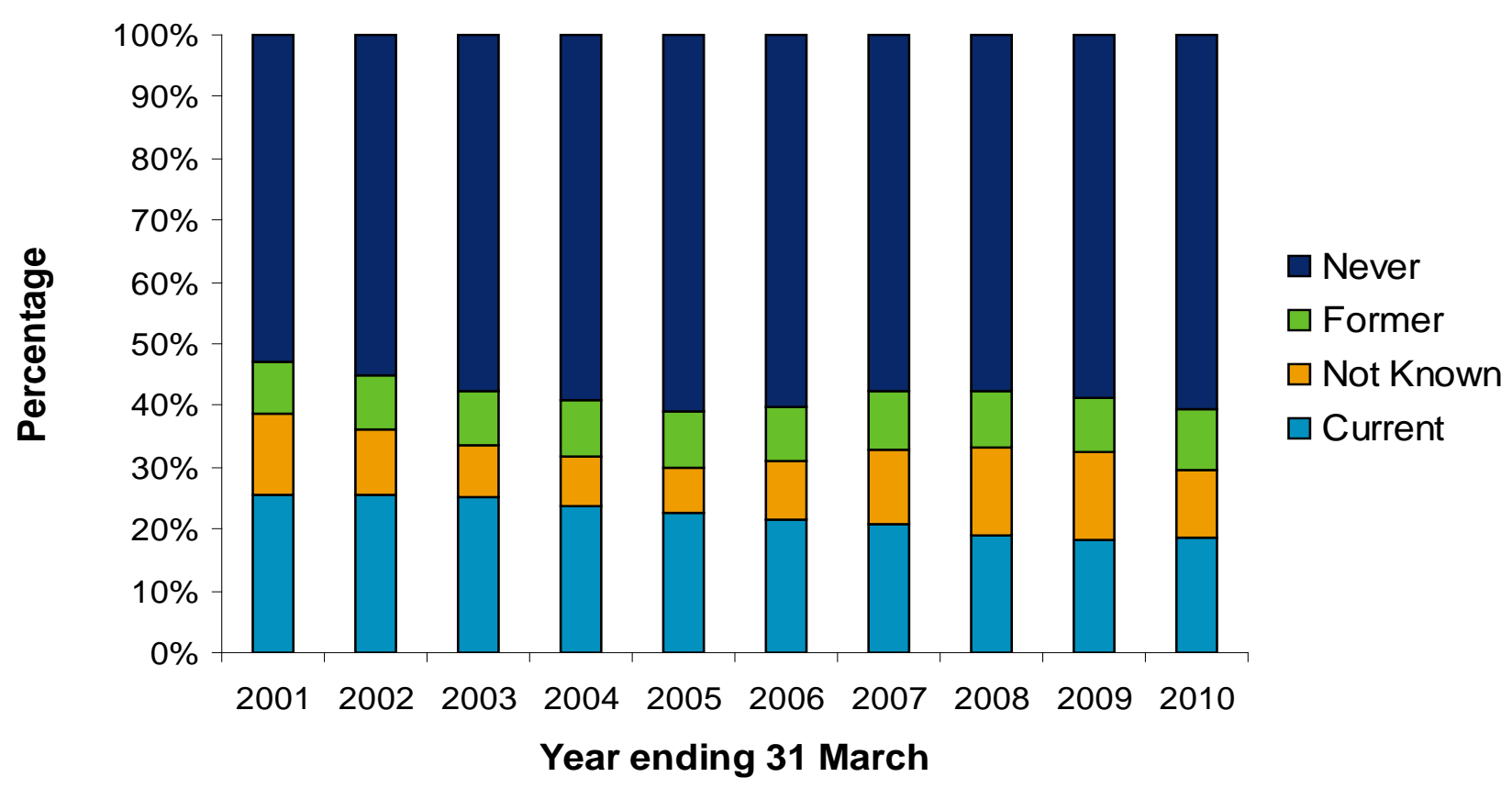

Source: SMR02

Please refer to footnotes at end of section.

Smoking at the first visit, all participating NHS boards of residence; 2001-2010, yle 31 March

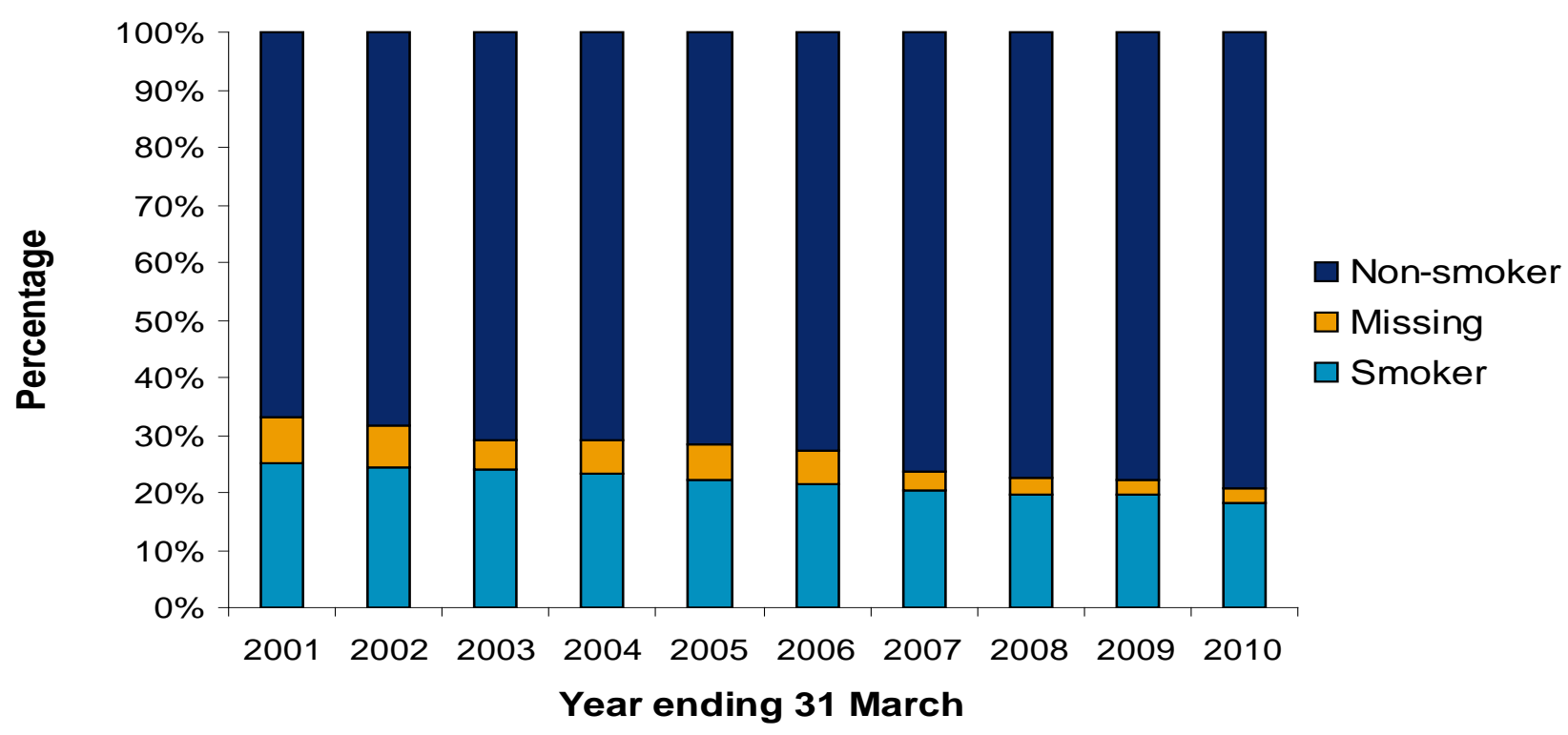


The SMR02 data demonstrates a fall in the level of women who are smokers at booking from $29.0 \%$ in 1995 to $18.8 \%$ in 2010 . However, the level of 'Not Known' has increased from $5.0 \%$ in 1995 to $10.7 \%$ in 2010 (a decrease of 3.5\% on 2009) and may include a proportion of smokers. Nevertheless, the SMR02 data are supported by the CHSP-PS data and suggest a reduction in the level of smoking in recent years. 


\section{Smoking by deprivation category}

For the following charts, the woman's deprivation has been derived using the Scottish Index of Multiple Deprivation 2009 (SIMD). SIMD5 is the least deprived quintile and SIMD1 is the most deprived.

\section{Smoking at booking by SIMD; yle 31 March $2010^{p}$}

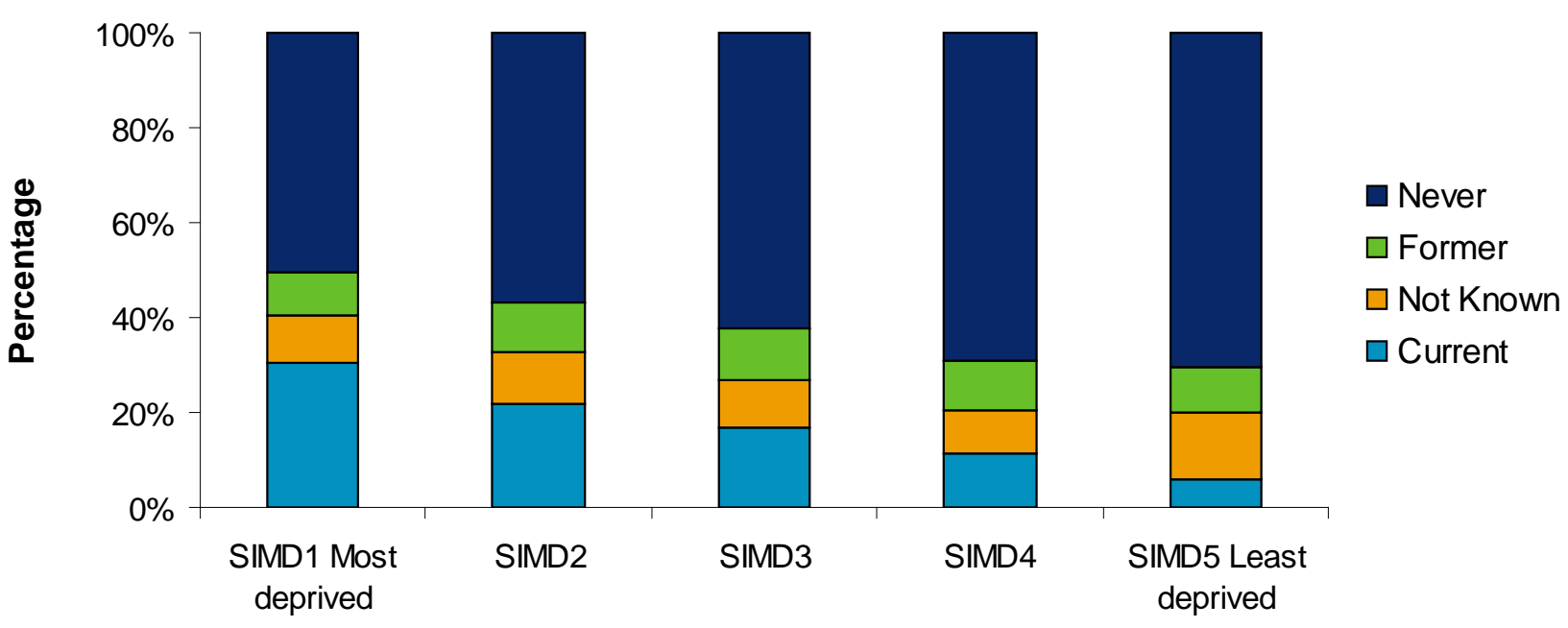

SIMD Quintile

Please refer to footnotes at end of section.

Smoking at first visit by SIMD; yle 31 March 2010

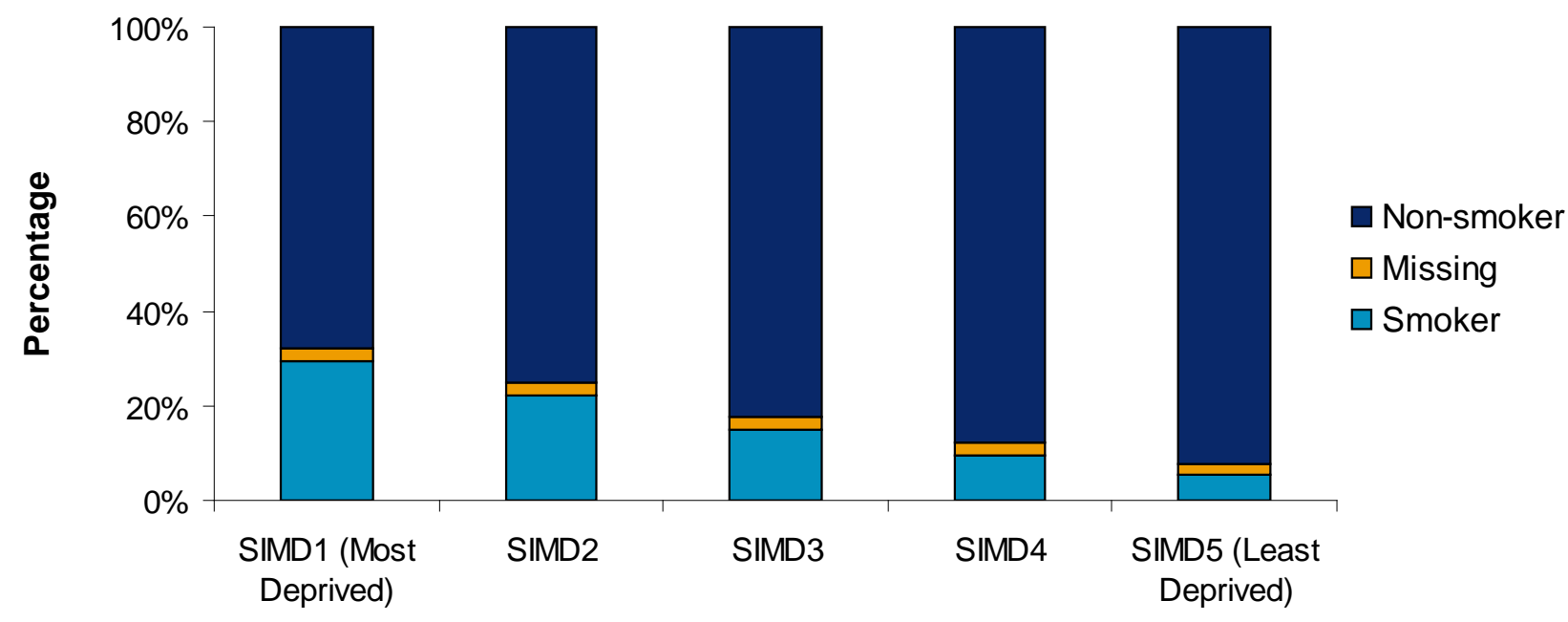

SIMD Quintile

Please refer to footnotes at end of section.

These charts demonstrate clearly the strong relationship between smoking and deprivation, with smoking at booking in 2010 ranging from $30.6 \%$ in SIMD1 to $6.1 \%$ in SIMD5. 


\section{Smoking by NHS Board}

The following charts show the variation in smoking across NHS Boards. Please note the wide variation in the 'Not Known' category, especially in 'Smoking at Booking' data.

Smoking at booking by NHS Board of residence; yle 31 March $2010^{p}$

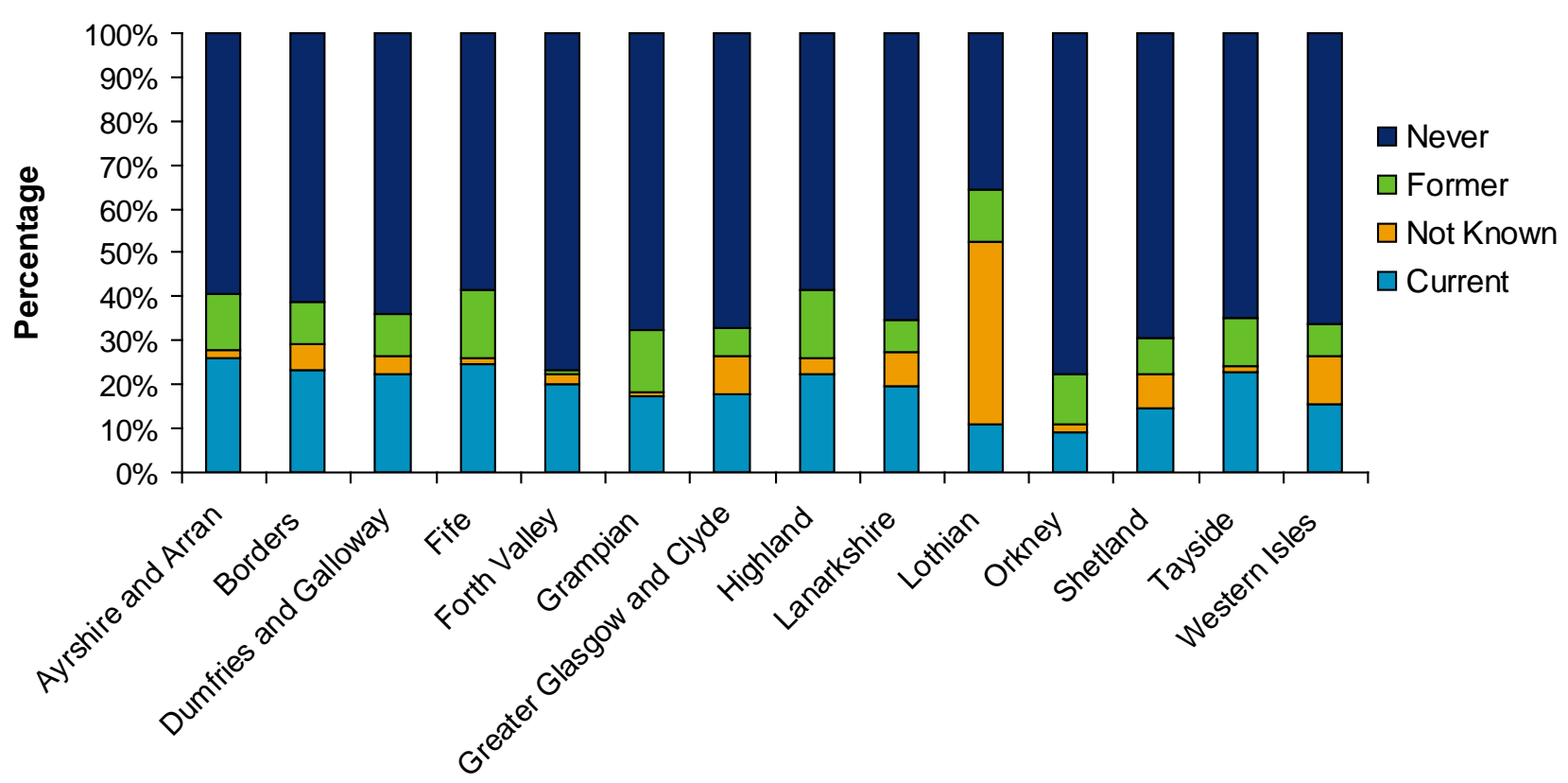

NHS Board of Residence

Source: SMR02

Please refer to footnotes at end of section.

Smoking at first visit by participating NHS Board of residence; yle 31 March 2010

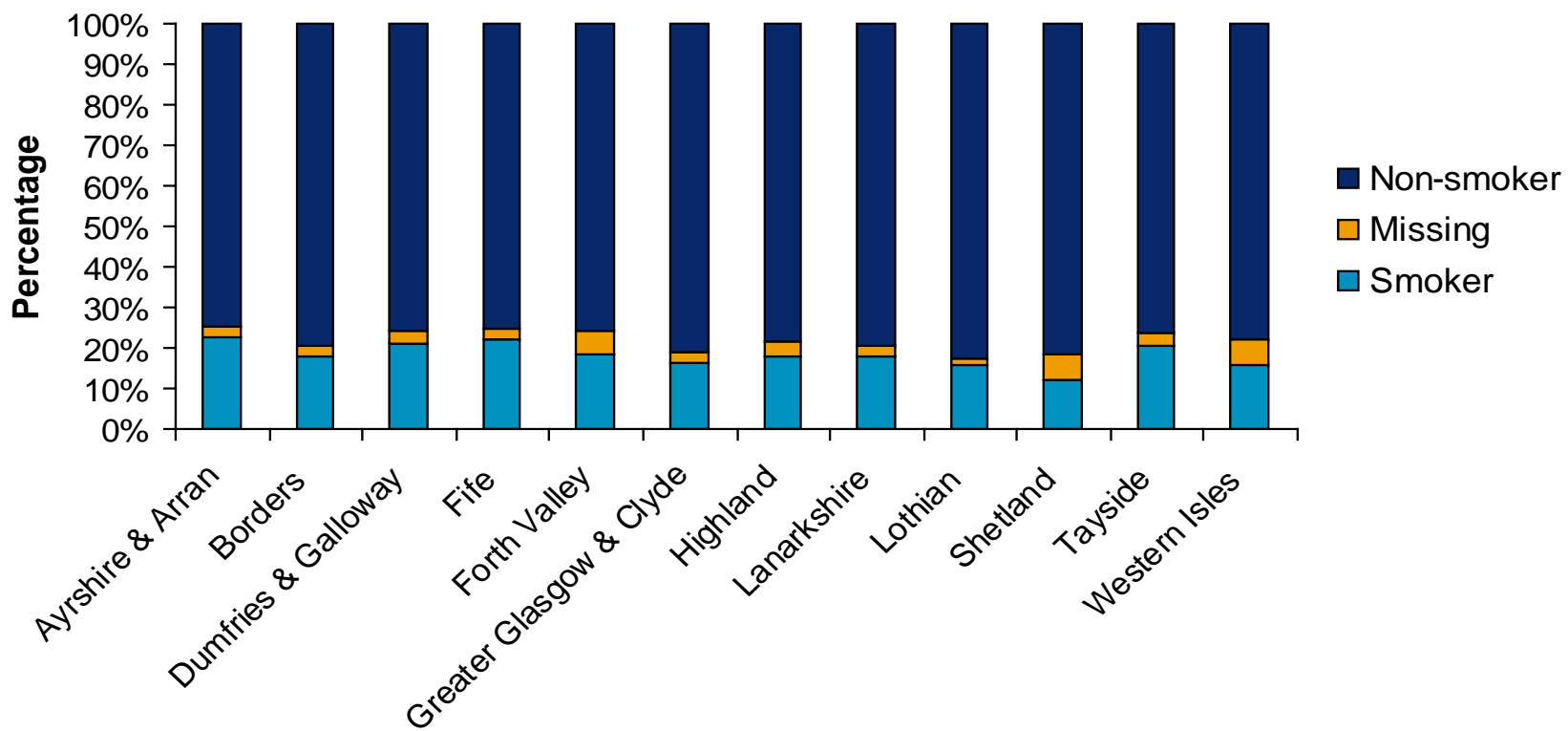

NHS Board of Residence 


\section{Smoking by mother's age}

Smoking at booking by maternal age; yle $31{\text { March } 2010^{p}}^{p}$

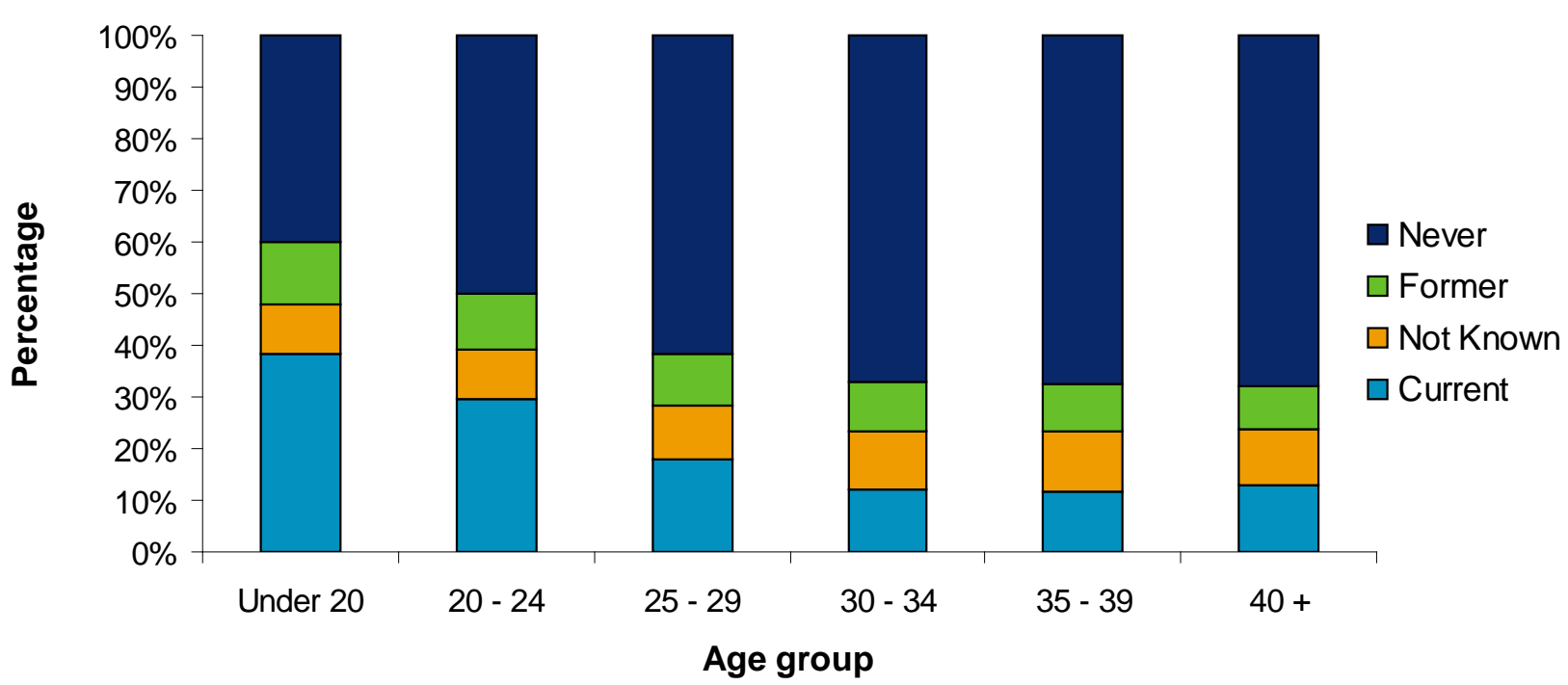

Source: SMR02

Please refer to footnotes at end of section.

Smoking at first visit by maternal age; yle 31 March 2010

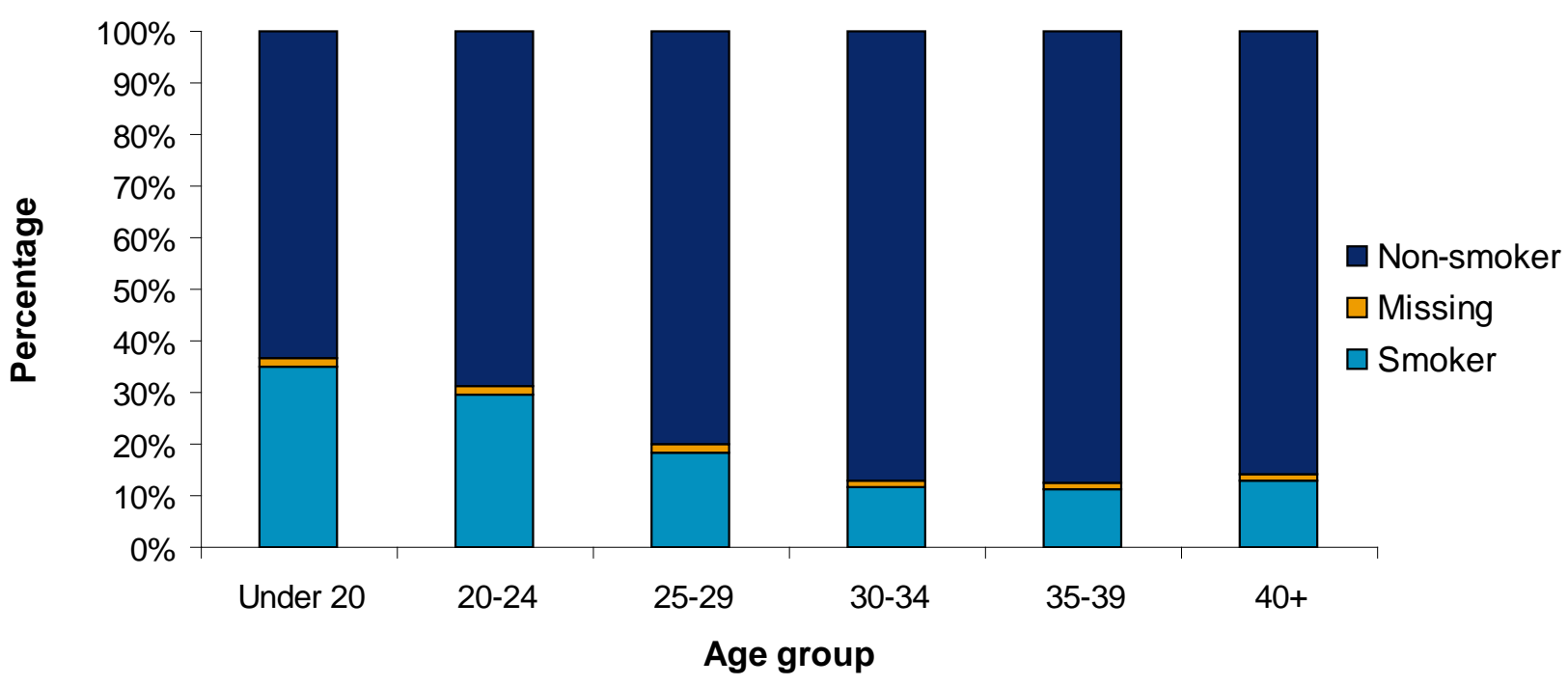

Source: CHSP-PS

Please refer to footnotes at end of section.

This chart shows that a mother's age is indirectly correlated to her smoking behaviour. With increasing age there is a decrease in smoking behaviour. The data also clearly illustrates that smoking behaviour in all age groups has declined between 2000 and 2010. 


\section{Footnotes relevant to Smoking and Pregnancy section}

\section{Smoking at Booking}

Excludes home births and births at non-NHS hospitals.

For analyses using SIMD 2009 ISD have changed their labelling and now label the categories as 1=most deprived to $5=$ =east deprived. Our policy of population-weighting the quintiles remains unchanged, so the datazones contained within each quintile will differ slightly to those presented in Scottish Government releases.

p - Provisional.

\# Please refer to notes on Accuracy of Smoking Data available on Appendix A1- Background information.

\section{Smoking at first visit}

These data are derived from the Child Health Systems Programme - Pre School system (CHSP-PS). CHSP-PS was established in 1991 and the number of participating boards has increased over the years. The 12 NHS Board areas now using the system account for approximately 89 percent of Scotland's pre-school population. The implementation dates of NHS Boards using the system are available at www.isdscotland.org/isd/4242.html. NHS Grampian and NHS Orkney do not participate in the CHSP-PS and are therefore not included in these figures.

For analyses using SIMD 2009 ISD have changed their labelling and now label the categories as 1=most deprived to $5=$ least deprived. Our policy of population-weighting the quintiles remains unchanged, so the datazones contained within each quintile will differ slightly to those presented in Scottish Government releases.

There are a small number of cases where it has not been possible to derive a SIMD category due to missing or invalid postcode information. These are included in the total. 


\section{Miscarriage}

Accurate assessment of the number of miscarriages (previously referred to as "spontaneous abortions") that occur is not possible as only miscarriages that require hospital inpatient or day-case treatment are recorded. Hospital based information is derived from two sources: the acute hospital inpatient and day-case record (SMR01) and the maternity inpatient and day case record (SMR02), with individual episodes being derived from only one of these sources. It is possible that some, particularly early, miscarriages are either managed solely by General Practitioners or may not be recognised by the women and so are never referred to hospital.

There is a general downward trend in the number of recorded miscarriages, falling from 7546 in 1998 to 5708 in 2010 . The table below shows the number of miscarriages by NHS board of residence and age group for year end $31^{\text {st }}$ March 2010.

Miscarriages ${ }^{1,2}$ by NHS board of residence and maternal age, yle 31 March $2010^{p}$

\begin{tabular}{|c|c|c|c|c|c|c|c|c|}
\hline \multirow[b]{2}{*}{ NHS board } & \multirow[b]{2}{*}{ Total } & \multirow[b]{2}{*}{ Rate $^{3}$} & \multicolumn{6}{|c|}{ Age of Mother } \\
\hline & & & $<20$ & $20-24$ & $25-29$ & $30-34$ & $35-39$ & $40+$ \\
\hline Scotland $^{4}$ & 5708 & 5.5 & 401 & 849 & 1236 & 1375 & 1231 & 616 \\
\hline Ayrshire and Arran & 395 & 5.8 & 36 & 80 & 64 & 85 & 89 & 41 \\
\hline Borders & 169 & 8.8 & 11 & 17 & 27 & 48 & 43 & 23 \\
\hline Dumfries and Galloway & 159 & 6.5 & 17 & 36 & 30 & 32 & 24 & 20 \\
\hline Fife & 436 & 6.1 & 41 & 71 & 109 & 96 & 89 & 30 \\
\hline Forth Valley & 267 & 4.6 & 15 & 40 & 56 & 53 & 66 & 37 \\
\hline $\begin{array}{l}\text { Grampian } \\
\text { Greater Glasgow \& }\end{array}$ & 1093 & 10.2 & 79 & 135 & 249 & 304 & 206 & 120 \\
\hline Clyde & 1204 & 4.7 & 80 & 191 & 268 & 269 & 265 & 131 \\
\hline Highland & 333 & 6.3 & 22 & 44 & 79 & 68 & 70 & 50 \\
\hline Islands ${ }^{5}$ & 25 & 2.2 & * & 8 & * & 8 & * & * \\
\hline Lanarkshire & 488 & 4.3 & 25 & 70 & 125 & 115 & 116 & 37 \\
\hline Lothian & 726 & 3.9 & 40 & 96 & 133 & 196 & 178 & 83 \\
\hline Tayside & 368 & 4.8 & 28 & 57 & 85 & 85 & 76 & 37 \\
\hline Other/Not Known & 45 & $x$ & * & * & * & 16 & * & * \\
\hline
\end{tabular}

Sources: SMR01 (acute hospital discharge summary) and SMR02 (maternity hospital discharge summary).

1. Miscarriages (spontaneous abortions) requiring hospital in-patient treatment.

2. Miscarriage is defined using ICD10 codes (from 1996 onwards) O02- Other abnormal products on conception,

including missed abortions and $\mathrm{O} 03$ - Spontaneous abortion.

3. Rate per 1,000 women aged 15-44 years.

4. Includes births where NHS board of residence is unknown or outwith Scotland

5. Orkney, Shetland and Western Isles NHS board of residence.

p Provisional

* Indicates values that have been suppressed due to the potential risk of disclosure.

Table 10: Miscarriage by NHS board 


\section{Glossary}

All births

Antenatal

Delivery

Deprivation Category

Elective Caesarean

Full term

Live Births

Low birthweight

Macrosomic

Maternity

Multiple birth

Parity

Postnatal

Pregnancy

Premature

Singleton birth

Still Births

Very low birthweight
When four or more babies are born, details about the babies are only recorded on the SMR02 for the first three babies delivered. However, the total number of births from the pregnancy are recorded.

Occurring before birth.

A delivery is a pregnancy resulting in a live or still birth.

The deprivation analyses on these webpages are based on either Carstairs deprivation quintiles1 or the Social Index of Multiple Deprivation (SIMD) according to the recommendations on this page. See footnotes at bottom of individual tables for which deprivation measure was used.

An elective caesarean section refers to a caesarean section, which has been planned in advance and in most cases will have been recommended for clinical reasons such as breech or multiple births or previous caesarean section. It may also be the case that the woman will have chosen this method of delivery for non-clinical reasons.

A birth is considered full-term if the delivery occurs during or after the 37th week of gestation.

A live birth is defined as a birth where the baby was born breathing or showing other signs of life.

Babies with a birth weight of less than 2,500 grams.

Babies with an abnormally large body size.

A pregnancy resulting in a live or still birth, with multiple births being counted only once.

A baby from a pregnancy resulting in more than one live or still birth.

Refers to the number of previous pregnancies resulting in a live or still birth.

Occurring after birth

The period during which a woman is pregnant.

A birth is considered premature if the delivery occurs before the 37th week of gestation.

A baby from a pregnancy resulting in only one live or stillbirth. The Registration of Births, Deaths and Marriages (Scotland) Act 1965 defines a stillbirth as a child which was born after the 24th week of pregnancy and which did not breathe or show any other sign of life.

Babies with a birth weight of less than 1,500 grams. 


\section{List of Tables}

\begin{tabular}{|c|c|c|c|}
\hline Table No. & Name & Time period & File \& size \\
\hline 1 & $\begin{array}{l}\text { Births by outcome; } \\
\text { - } \text { Scotland } \\
\text { - } \text { NHS board of residence } \\
\text { - } \text { Local Council Area } \\
\end{array}$ & $\begin{array}{l}1976-2010 \\
1998-2010 \\
1998-2010 \\
1998-2010\end{array}$ & Excel $[495 \mathrm{~kb}]$ \\
\hline 2 & $\begin{array}{l}\text { Maternities by maternal age; } \\
\text { - Scotland } \\
\text { - } \text { NHS board of residence } \\
\text { - Local Council Area } \\
\text { - Community Health Partnership }\end{array}$ & $\begin{array}{l}1976-2010 \\
1998-2010 \\
1998-2010 \\
1998-2010\end{array}$ & Excel [313kb] \\
\hline 3 & $\begin{array}{l}\text { Maternities (first birth and all births) by } \\
\text { maternal age and deprivation; Scotland and } \\
\text { NHS board of residence }\end{array}$ & $1998-2010$ & Excel [497kb] \\
\hline 4 & $\begin{array}{l}\text { Live births by mode of delivery and } \\
\text { induction; } \\
\text { - Scotland } \\
\text { - NHS board of residence } \\
\text { - hospital }\end{array}$ & $\begin{array}{l}1976-2010 \\
1998-2010 \\
1998,2000 \\
2005,2009 \\
2010\end{array}$ & Excel [467kb] \\
\hline 5 & $\begin{array}{l}\text { Live births (all, singleton and multiple) by } \\
\text { birthweight and gestation; Scotland and } \\
\text { NHS board of residence }\end{array}$ & $1976-2010$ & Excel [1531kb] \\
\hline 6 & $\begin{array}{l}\text { All births (live and still), pre-term and full } \\
\text { term by birthweight; Scotland and NHS } \\
\text { board of residence }\end{array}$ & $1976-2010$ & Excel [401kb] \\
\hline 7 & $\begin{array}{l}\text { Live births (all, singleton and multiple) by } \\
\text { birthweight and deprivation; Scotland and } \\
\text { NHS board of residence }\end{array}$ & $1998-2010$ & Excel [501kb] \\
\hline 8 & $\begin{array}{l}\text { Smoking history at booking; } \\
\text { - } \text { Scotland } \\
\text { - } \text { NHS board of residence } \\
\text { - } \text { maternal age }\end{array}$ & $\begin{array}{l}2001-2010 \\
2001-2010 \\
2001-2010 \\
2001-2010\end{array}$ & Excel [639kb] \\
\hline 9 & $\begin{array}{l}\text { Smoking at public health nurse/health } \\
\text { visitor's first visit; } \\
\text { - Scotland } \\
\text { - NHS board of residence } \\
\text { - deprivation } \\
\text { - } \text { maternal age }\end{array}$ & $\begin{array}{l}2001-2010 \\
2001-2010 \\
2001-2010 \\
2001-2010\end{array}$ & Excel [280kb] \\
\hline 10 & $\begin{array}{l}\text { Miscarriages; by NHS board of residence } \\
\text { and maternal age }\end{array}$ & $1998-2010$ & Excel [104kb] \\
\hline 11 & Small for gestational age & $2001-2010$ & Excel (214kb) \\
\hline
\end{tabular}




\section{List of Charts}

\begin{tabular}{|c|l|c|c|}
\hline \multicolumn{1}{c}{ Chart No. } & \multicolumn{1}{c|}{ Name } & \multicolumn{1}{c|}{ Fime period } & File \& size \\
\hline 1 & NRS birth registrations v SMR02 births & $1855-2010$ & Excel [39kb] \\
\hline 2 & SMR02 from 1980 & Excel [52kb] \\
\hline 3 & Lirst birth by maternal age and deprivation & 2010 & Excel \\
\hline 4 & Live singleton births by mode of delivery & $1998-2010$ & Excel [55kb] \\
& $\begin{array}{l}\text { Live singleton births by birthweight and } \\
\text { gestation }\end{array}$ & $1998-2010$ & Excel [59kb] \\
\hline 5 & Smoking at booking by deprivation & $1998-2010$ & Excel [59kb] \\
\hline 6 & Small for gestational age & $1998-2010$ & Excel [214kb] \\
\hline
\end{tabular}




\section{Contact}

\section{Kenny McIntyre}

Senior Information Analyst Nss.isdmaternity@nhs.net

01312756557

\section{Kirsten Monteath}

Senior Information Analyst

Nss.isdmaternity@nhs.net

01312756839

\section{Further Information}

Further information can be found on the ISD website 


\section{Appendix}

\section{A1 - Background Information \\ Maternity Data Source (inpatients and day cases) \\ Hospital based maternity and birth data are derived from the maternity inpatient and day case record (SMR02).}

\section{Births}

In Scotland the most reliable number of births is based on the civil registration system administered by the National Records of Scotland (NRS). However, NRS numbers are based on the date of registration of the births rather than the date of birth, so that a child born in late December of one year may not be registered until the following year. The data presented on these web pages are derived from SMR02 (maternity hospital records) and are based on date of discharge from hospital. Unlike civil registrations, there is no legal requirement to complete the maternity return, with under-recording of home births being one area for particular concern.

\section{Coverage and completeness}

Since 1976 the SMR02 system has achieved national coverage of approximately 98 per cent of all births and pregnancies and includes a wide range of clinical data such as birthweight, gestational age, mode of delivery, induction and outcome of pregnancy. More recently, information on smoking during pregnancy (1993/94) and drug and alcohol misuse (2003/04) has been introduced. There are, however, concerns about the completeness and accuracy of the recording of these variables. See note below on issues regarding smoking data. Information on drug misuse in pregnancy and on babies discharged from neonatal care can also be found in the Drug Misuse Statistics Scotland report.

Delivery records account for approximately half of all SMR02 discharges each year with antenatal, postnatal and abortion episodes forming the remaining discharges (see also Teenage Pregnancy and Abortion Act Statistics).

Tables in this website which are based on SMR02 information exclude home births. Detailed birth information about the fourth or subsequent babies (third prior to 1997) in a multiple delivery is also not available from this source, as the SMR02 can only facilitate the recording of information on three babies (two prior to 1997).

The data for year ending 31 March 2010 should be regarded as provisional and will be revised at the update next year. Throughout this publication, figures shown for each year relate to live births, still births, maternities, or pregnancies which occurred in the year ending 31 March. The one exception to this is the section on NRS birth registrations v's SMR02 births, which is based on year ending 31 December.

\section{Data issues}

In previous publications, a very small number of births in a delivery were recorded as 9 (not known) and these were recoded and counted as singleton births. This has now been revised and they are no longer counted as a singleton birth. A number of tables have been affected by this and will now more accurately reflect the number of births as recorded on an SMR02 record.

Population data used for calculating age specific rates are provided by the National Records of Scotland (NRS). 


\section{Scottish Index of Multiple Deprivation 2009 (SIMD 2009)}

In a change to the previous SIMD analyses, the 2009 version have been reversed to match the English version. Deprivation quintile 1 is now the most deprived and deprivation quintile 5 , the least deprived.

\section{Accuracy of Smoking at Booking Data}

Data on smoking behaviour is based on self-reported information obtained from mothers at their ante-natal booking visit in the community or at hospital. The 'smoking at booking' data item was introduced in 1993/94 and it should be noted that, particularly in the earlier years and again more recently, this information is not always recorded and therefore can affect the results. Because of concerns about the quality of 'smoking at booking' data, care should be taken in interpreting the results.

\section{Smoking at First Visit}

The CHSP PS system, from which these statistics are derived, facilitates the call/recall of children for reviews from shortly after birth until school entry and records results. The system is dynamic, with ongoing updating of records. For this reason there can be very minor changes to previously published data for previous years, however any changes are negligible.

\section{Revisions to Smoking at First Visit data}

Beyond any negligible changes in the reported figures due to the dynamic nature of CHSP PS data, a new methodology has been implemented to improve the accuracy of the NHS Board and Scottish Index of Multiple Deprivation (SIMD 2009) quintile statistics for all years presented. The overall Scotland figures and data by maternal age are not affected by the new methodology. This revision does not affect the overall interpretation or conclusions to be drawn from previously published data. The impact on the reported rates at NHS Board level is mainly in the range -0.4 to 0.4 percentage points and by SIMD quintile is mainly in range -1.0 to 1.0 percentage points. Slightly larger differences may be seen in some Boards or quintiles for some years.

\section{Background information and new methodology for Smoking at First Visit data} Each year's release of smoking at First Visit statistics has been based on the latest available data from the CHSP PS which allows for additions and amendments to the review data. Limitations in the postcode derived information have been identified such that where a child's postcode of residence has changed, in some instances the derived NHS Board of residence and SIMD quintile may not reflect where the child lived at the time of their First Visit review.

Functionality to ensure the child's postcode at review is recorded on CHSP PS was added to the system in June 2011, and will be available for review data recorded in the system from that date. For review data recorded prior to June 2011, due to the limitations identified, a change to the methodology used to derive the NHS Board and SIMD quintile statistics has been implemented to improve the accuracy of these statistics as follows:

- NHS Board figures are now based on NHS Board of review as recorded on CHSP PS. For the vast majority of children, the NHS Board where they received their First Visit review will be the same as their NHS Board of residence, although there will be some children who live in one NHS board area and attend a practice in a neighbouring NHS board. Records on CHSP PS for the former Argyll \& Clyde board area have been mapped to either NHS Greater Glasgow \& Clyde or NHS Highland 
board areas based on the child's postcode at birth as derived from National Records of Scotland (formerly the General Register Office for Scotland) birth registrations. Argyll \& Clyde board area ceased to exist on 31st March 2006 and the administration split into two sub-areas that now fall under the administration of NHS Greater Glasgow \& Clyde and NHS Highland.

- SIMD quintiles are now based on the child's birth postcode as derived from National Records of Scotland (formerly the General Register Office for Scotland) birth registrations. Birth postcode is a proxy for postcode at review as few families will move home between the birth of their child and the First Visit review. For a small proportion of records it is not possible to assign a birth postcode and/or derive a SIMD quintile. 


\section{A2 - Publication Metadata (including revisions details)}

\begin{tabular}{|c|c|}
\hline $\begin{array}{l}\text { Metadata } \\
\text { Indicator }\end{array}$ & Description \\
\hline $\begin{array}{l}\text { Publication } \\
\text { title }\end{array}$ & Births in Scottish Hospitals \\
\hline Description & $\begin{array}{l}\text { Annual update to information on births in Scottish NHS hospitals. This } \\
\text { includes information on the mother, the delivery and the baby, available at } \\
\text { various geographies including NHS Board, Local Council Area, } \\
\text { Community Health Partnership and hospital level. }\end{array}$ \\
\hline Theme & Health and Social Care. \\
\hline Topic & Maternity and pregnancy services. \\
\hline Format & Excel workbooks. \\
\hline Data source(s) & $\begin{array}{l}\text { SMR02 (maternity hospital discharge summary) and SMR01 (acute } \\
\text { hospital discharge summary) in miscarriage data. }\end{array}$ \\
\hline $\begin{array}{l}\text { Date that data } \\
\text { are acquired }\end{array}$ & 1st June 2011 (two months prior to release). \\
\hline Release date & 30 August 2011 \\
\hline Frequency & Annual \\
\hline $\begin{array}{l}\text { Timeframe of } \\
\text { data and } \\
\text { timeliness }\end{array}$ & $\begin{array}{l}\text { Data for financial year } 31 \text { March } 2010 \text {. The delay between data timeframe } \\
\text { and date of publication timeliness is mainly due to delays in data } \\
\text { submission from some NHS boards. Publication of data is generally } \\
\text { delayed until SMR02 submission is estimated to be around } 97-98 \% \\
\text { complete. }\end{array}$ \\
\hline $\begin{array}{l}\text { Continuity of } \\
\text { data }\end{array}$ & Reports data from 1975/76. \\
\hline $\begin{array}{l}\text { Revisions } \\
\text { statement }\end{array}$ & $\begin{array}{l}\text { Data are generally noted as provisional (due to a small shortfall in } \\
\text { completeness of data) at time of publication. The data are then revised at } \\
\text { next year's update. } \\
\text { Concepts and definitions }\end{array}$ \\
\hline $\begin{array}{l}\text { Revisions } \\
\text { relevant to this } \\
\text { publication }\end{array}$ & $\begin{array}{l}\text { Maternal Smoking at First Visit figures for all years revised. See Appendix } \\
\text { A1 Smoking at First Visit section. }\end{array}$ \\
\hline $\begin{array}{l}\text { Concepts and } \\
\text { definitions }\end{array}$ & http://www.isdscotland.org/Health-Topics/Maternity-and-Births/Births \\
\hline $\begin{array}{l}\text { Relevance } \\
\text { and key uses } \\
\text { of the statistics }\end{array}$ & $\begin{array}{l}\text { Making information publicly available for planning, epidemiology, provision } \\
\text { of services and the statistics provides comparative information. }\end{array}$ \\
\hline Accuracy & $\begin{array}{l}\text { SMR02 data are subjected to validation on submission. The figures are } \\
\text { compared to previous years' figures and to expected trends. The SMR02 } \\
\text { data are also occasionally assessed for accuracy by ISD's Data Quality } \\
\text { Assurance -- see latest report 'Data Quality Assurance (Assessment of } \\
\text { Maternity Data) 2008-09' Report at http://Www.isdscotland.org/Products- } \\
\text { and-Services/Data-Quality }\end{array}$ \\
\hline Completeness & $\begin{array}{l}\text { There is generally around a } 2 \text { - 3\% shortfall in the number of births when } \\
\text { compared to the National Records of Scotland (NRS) birth registrations, } \\
\text { formerly General Register Office Scotland (GROS). Some of this shortfall } \\
\text { is due to data on home births not being available from SMR02 data } \\
\text { source. For comparison of SMR02 births v NRS registrations see: } \\
\text { http://www.isdscotland.org/Health-Topics/Maternity-and- }\end{array}$ \\
\hline
\end{tabular}




\begin{tabular}{|c|c|}
\hline & Births/Publications/2011-08-30/mat bb chart1.xls \\
\hline Comparability & $\begin{array}{l}\text { Maternity data for England are published by NHS information Centre at } \\
\text { HES Online } \\
\text { (http://www.hesonline.nhs.uk/Ease/servlet/ContentServer?siteID=1937\&ca } \\
\text { tegoryID=1009) - some of this will be directly comparable with Scottish } \\
\text { published data e.g. birthweight, gestation. Where directly comparable, } \\
\text { Scottish maternity data are regularly provided to ONS, Department of } \\
\text { Health for contribution to both UK and International reports/databases e.g. } \\
\text { UK Health Statistics, Social Trends, European Health for All database. In } \\
\text { these comparisons, data are provided only at national (Scotland) level or } \\
\text { may be aggregated to UK. }\end{array}$ \\
\hline Accessibility & $\begin{array}{l}\text { It is the policy of ISD Scotland to make its web sites and products } \\
\text { accessible according to published guidelines. }\end{array}$ \\
\hline $\begin{array}{l}\text { Coherence } \\
\text { and clarity }\end{array}$ & $\begin{array}{l}\text { Births in Scottish Hospital tables are accessible via the ISD website at } \\
\text { http://www.isdscotland.org/Health-Topics/Maternity-and-Births/Births } \\
\text { Drop down menus are presented where appropriate e.g. for selection of } \\
\text { geography i.e. NHS board/local council area/community health partnership } \\
\text { or for selection of singleton/multiple/all births or live/stillbirths/total births. }\end{array}$ \\
\hline $\begin{array}{l}\text { Value type } \\
\text { and unit of } \\
\text { measurement }\end{array}$ & Numbers and crude rates are presented. \\
\hline Disclosure & $\begin{array}{l}\text { The ISD protocol on Statistical Disclosure Protocol is followed: } \\
\text { http://www.isdscotland.org/Products-and-Services/Data-Protection-and- } \\
\text { Confidentiality }\end{array}$ \\
\hline $\begin{array}{l}\text { Official } \\
\text { Statistics } \\
\text { designation }\end{array}$ & National Statistics. \\
\hline $\begin{array}{l}\text { UK Statistics } \\
\text { Authority } \\
\text { Assessment }\end{array}$ & Awaiting assessment by UK Statistics Authority. \\
\hline Last published & 31 August 2010 \\
\hline Next published & 28 August 2012 \\
\hline $\begin{array}{l}\text { Date of first } \\
\text { publication }\end{array}$ & 1975 \\
\hline Help email & Nss.isdmaternity@nhs.net \\
\hline $\begin{array}{l}\text { Date form } \\
\text { completed }\end{array}$ & 17 August 2011 \\
\hline
\end{tabular}




\section{A3 - Early Access details (including Pre-Release Access)}

\section{Pre-Release Access}

Under terms of the "Pre-Release Access to Official Statistics (Scotland) Order 2008", ISD are obliged to publish information on those receiving Pre-Release Access ("Pre-Release Access" refers to statistics in their final form prior to publication). The standard maximum Pre-Release Access is five working days. Shown below are details of those receiving standard Pre-Release Access and, separately, those receiving extended Pre-Release Access.

Standard Pre-Release Access:

Scottish Government Health Department

NHS Board Chief Executives

NHS Board Communication leads

\section{Extended Pre-Release Access}

Extended Pre-Release Access of 8 working days is given to a small number of named individuals in the Scottish Government Health Department (Analytical Services Division). This Pre-Release Access is for the sole purpose of enabling that department to gain an understanding of the statistics prior to briefing others in Scottish Government (during the period of standard Pre-Release Access).

Scottish Government Health Department (Analytical Services Division) 